castellano, es la claridad del autor para capturar los problemas biológicos, amalgamarlos con las raíces físico-químicas de la materia y entrelazar dicho conocimiento con las bases filosóficas del pensamiento evolutivo. Sin duda un texto que ilumina en muchos aspectos y que es recomendable para lecturas de pre y postgrado.

\section{LITERATURA CITADA}

ALbert R, H JEONG \& AL BARABÁsi (2000) Error and attack tolerance of complex networks. Nature $406: 378-382$.

BATESONG (1979) Mind and nature: a necessary unity. Bantam Books, New York, New York. 259 pp.

EIGEN M (1971) Self-organization of matter and the evolution of biological macromolecules. Naturwissenchaften 58: 465-523.

EIgEN M \& P SCHUSTER (1978) The hypercycle: a principle of natural self-organization. Part C: the realistic hypercycle. Naturwissenchaften 65: 341-369.
KAUFFMANN SA (1993) The origins of order: selforganization and selection in evolution. Oxford University Press, New York, New York. 709 pp.

KAUFFMANN SA (1995) At home in the universe: the search for laws of self-organization and complexity. Oxford University Press, New York, New York. 321 $\mathrm{pp}$.

JEONG H, B TOMBOR, $R$ ALBERT, ZN OLTVAI \& AL BARIBÁSI (2000) The large-scale organization of metabolic networks. Nature 407: 651-654.

GALLARDO MH (1997) Determinismo estructural: teoría científica o dogma? Revista Chilena de Historia Natural 70: 315-319.

VON FOERSTER H (1984) Observing systems. Second edition. Intersystems Publications, Seaside, California. $331 \mathrm{pp}$.

MILTON GALLARDO

Instituto de Ecología y Evolución

Universidad Austral de Chile

\title{
Mamíferos de Chile
}

\author{
MUÑOZ-PEDREROS A \& J YÁÑEZ (eds) (2000) Centro de Estudios Agrarios y \\ Ambientales (CEA) Ediciones, Valdivia, Chile. viii +464 pp.
}

A pesar de ser carcinólogo y tal vez por una vieja amistad con gran parte de los 26 colaboradores de esta obra, hace casi un año, como Director del Museo Nacional de Historia Natural, presenté este libro en su lanzamiento. Durante este tiempo ningún mastozoólogo nacional ha hecho algún comentario sobre este libro para la Revista Chilena de Historia Natural y esto seguramente se debe a que todos los que conocen el tema están implicados en su autoría".

Fui, creo yo, el primer usuario ilegal del libro cuando estaba en estado de maqueta, lo utilicé como guía clandestina de los cursos que imparto en la Universidad de Chile y lo hallé fantástico, (claro, como toda obra humana, perfectible).

Varias cosas me gustaron de este libro. Una de ellas es el que sea bastante ecuménico, no sólo por la universalidad de temas mastozoológicos que trata, sino por las posibilidades de alcanzar a un público variopinto. Con pocas excepciones, el lenguaje se sitúa en un justo término medio entre el argot científico y la divulgación de los conocimientos.

Es evidente que los autores están conscientes de una realidad objetiva: los mamíferos son uno de los grupos zoológicos que mayor impacto debe alcanzar en las preferencias populares (junto con aves, insectos y moluscos). Pero esta misma ventaja les genera una obligación: la de usar un lenguaje accesible al vasto público, y creo que han aprendido a hacerlo. Otro mérito: han publicado su libro, con lo cual le dejan una vara alta a los ornitólogos y malacólogos. Vamos revisándolo:

El capítulo 1 es un capítulo introductorio. José Yáñez entrega una sucinta sinopsis del grupo, sus características generales, origen y evolución, todo en el lenguaje fácil y accesible de un científico que cultiva con igual destreza la investigación y la divulgación, mientras que Andrés Muñoz presenta una necesaria visión antropocéntrica del grupo cuando nos habla de su importancia, los usos que les da el hombre (carne, cuero, lana, y, hoy día, fotosafaris), acerca de su domesticación (menciona crianza de cuyes y degúes por pueblos prehispánicos) y de su interés en cuanto plagas o su importancia epidemiológica.- Los problemas de conservación, incluyendo legislación, comercio y crianza en cautividad, son adecuadamente expuestos por Agustín Iriarte, que sin duda tiene autoridad en la materia. 
En el gran capítulo 2, titulado Descripción de las Especies Vivientes, hay un metódico tratamiento de cada una las 150 especies chilenas, agrupadas en 85 géneros, 28 familias y nueve órdenes. Cada subcapítulo corresponde a un orden y tiene la autoría de uno a tres especialistas en el grupo. El último de los subcapítulos hace referencia los mamíferos exóticos asilvestrados en Chile, donde se consideran 15 especies, desde los triviales conejos hasta los insospechados muflones y renos. El tratamiento para cada especie incluye su nombre científico actualizado, la enumeración de las subespecies, las características morfológicas, distribución, hábitat, etología, ecología y estado de conservación, así como una fotografía o ilustración del animal. Quisiera apuntar un par de críticas: (1) hubiera sido interesante consignar la sinonimia, tan importante en algunos grupos como los felinos y los roedores cuyos nombres cambian con mayor frecuencia de lo uno quisiera; (2) la reproducción de las fotografías no logró superar algunos problemas técnicos de impresión (aparentemente en la digitalización de las imágenes).

El capítulo 3 se titula Ecología de los Mamíferos. En un primer artículoÁngel spotorno y Laura Walker hacen una presentación clara y pedagógica acerca del origen y evolución del grupo, la que es complementada por los dos siguientes trabajos. Al escribir sobre la paleoecología, Javier Simonetti hace énfasis en el conocimiento de la paleofauna reciente, la que coincide con la aparición del hombre en la región. Hace notar que los mayores aportes han sido hechos o promovidos por arqueólogos, lo que, razonablemente, crea un panorama confuso acerca de la validez taxonómica de muchos hallazgos. Ciertamente, faltan paleontólogos de vertebrados en Chile. Luis Contreras en el artículo sobre biogeografía del grupo, resalta la abundancia de ratones y la escasez de murciélagos y detecta la existencia de seis agrupaciones biogeográficas que llama "nodos", muy razonables a la luz de los datos que expone. Más adelante, Francisco Bozinovic escribe uno de los capítulos a mi juicio mejor logrado, el que se refiere a la ecofisiología, donde explica cómo hacen y por qué hacen las cosas que hacen los animales para sacar el máximo de provecho de lo que pueden hacer. Se refiere al negocio de vivir, es decir, obtener la mayor calidad de vida al más bajo costo. Baraja elementos como tamaño corporal, dietas, climas, metabolismo, ciclos biológicos y conducta.

El trabajo de Roberto Murúa sobre ecología de poblaciones llama la atención sobre las tentaciones de los análisis matemáticos y resucita la definición "operacional" de Cole. Plantea también algunas situaciones más bien polémicas, como la de las fronteras de una población o de la realidad de las metapoblaciones. Si bien se extiende en el uso (y recetas) de las tablas de vida, me parece más valioso por las inquietudes que crea que por los conocimientos que expone.

El artículo de Fabián Jaksic acerca de la ecología de comunidades me parece esencialmente pedagógico y utilitario, lo que es excelente en un libro como éste. Ordena los tipos de estudios de comunidades y revisa, en cada caso, lo que se ha hecho en Chile. Es un trabajo como para hacerlo leer a estudiantes, porque no sólo describe los tipos de investigaciones que se hacen, sino que entrega un estado del arte en Chile hoy.

Más adelante, Javier Simonetti presenta un artículo acerca de un área poco desarrollada en Chile: la ecología experimental y hace un estudio histórico de los trabajos realizados en Chile, no de sus resultados. Como es de esperar, la mayoría se refiere a pequeños mamíferos y el 66 o del total está realizado en el matorral esclerófilo de la zona central. Los principales temas apuntan a problemas tróficos (depredador/presa, etc.), uso de espacio, perturbaciones de origen antrópico, ecofisiología conductual y demografía.

El capítulo 4 se refiere a la identificación y clasificación de los mamíferos, como es comprensible, un primer artículo (Luz González y Juan Carlos Torres) hace un recuento de los principales elementos de análisis sistemático, desde las tradicionales herramientas que aporta la morfología hasta las más modernas, como electroforesis y zimogramas, cariología y estudios de ADN. Otro tema muy específico de apoyo a la taxonomía son los estudios de morfología de los espermatozoides, a los que se refiere Rufino Feito en el segundo artículo de este capítulo. En Chile hay poco trabajo en este tema. Se ha descrito el espermatozoide del coipo, de otros pocos roedores, del pudú y de la llama. La médula de este capítulo es la presentación de una clave de identificación de los mamíferos de Chile (José Yáñez, Manuel Tamayo y Herman Núñez), donde se incorporan algunas ilustraciones, y sobre la cual no nos pronunciamos porque no la hemos puesto a prueba, única forma de juzgar el valor de una clave. Una lista sobre el significado de los nombres científicos (José Yáñez y Manuel Tamayo), una discusión acerca de las colecciones mastozoológicas de Chile (Gisela González y José Yáñez) y un trabajo acerca de la preparación y conservación de muestras (José Yáñez), completan la unidad de este capítulo.

El capítulo 5 se titula Técnicas y Métodos de Estudio. Este capítulo se inicia con un trabajo sobre capturas y recolectas (José Yáñez). En él se 
ocupa desde la legislación que regula la recolección hasta de las técnicas de trampeo, uso de cebos, marcajey recaptura, trasladoy mantención de animales, así como de las variables que influyen en las probabilidades de captura. Otras técnicas de estudio que se analizan son aquéllas que dicen relación con la determinación de edad (Luz González), con prácticas de histología convencional (Manuel Tamayo), además de tres temas que Jaime Rau demuestra manejar con autoridad: las técnicas de detección de animales, los análisis de ecología trófica y la cuantificación de la diversidad.

Podemos leer a continuación un escrito sobre un tema siempre conflictivo en los estudios de terreno de los mamíferos: la estimación de la densidad poblacional. En él, Roberto Murúa describe métodos y da recetas, pero siempre ofrece un análisis crítico de los resultados que se pueden obtener. A pesar de la obligatoria brevedad del texto, se presenta un abanico amplísimo de métodos, desde los literalmente pedestres conteos de huellas, hasta los censos aéreos y paquetes computacionales.

Completa el capítulo una interesante bibliografía comentada por Manuel Tamayoy José Yáñez, en que dividen la información consultada en cinco categorías: Obras Generales (53), Obras Sobre Mamíferos de Sudamérica (25), Obras Sobre Mamíferos de Chile (22), Obras Sobre Grupos Determinados de Mamíferos Chilenos (16) y Publicaciones sobre Faunas Regionales (43), con un total de 159 asientos bibliográficos. Existe también, al final un breve glosario, que hubiéramos querido ver más extenso para mejorar la digestibilidad en lectores principiantes, pero no menos respetables, y un índice de nombres científicos y comunes.

En resumen, tenemos entre manos un libro interesante, entretenido y motivador. Creo que será de extrema utilidad preferentemente a estudiantes de enseñanza superior, a quienes se inicien en el estudio de este grupo animal o a profesores, lo que garantiza un cierto efecto multiplicador. Igualmente a administradores de fauna, los que deciden situaciones ambientales y los políticos preocupados por nuestra biodiversidad.

Seguramente nadie lo va a leer con el apasionamiento con que se lee una novela de Hernán Rivera Letelier, pero serán muchos los que, al cabo de cinco años, lo tendrán manoseado y desencuadernado. Y creo que el éxito de un libro se mide objetivamente por la cantidad de veces que se abre y por la velocidad con que se desencuaderna (naturalmente, a igualdad de calidad de encuadernación) .

Reitero mis felicitaciones a los autores y a los gestores de la iniciativa. Y yo me felicito de tener en mi biblioteca, ipor fin!, un buen libro de zoología chilena.

ALBERTO CARVACHO

Museo Nacional de Historia Natural 